\title{
Paeoniflorin ameliorates acute necrotizing pancreatitis and pancreatitis-induced acute renal injury
}

\author{
PENG WANG, WEIXING WANG, QIAO SHI, LIANG ZHAO, \\ FANGCHAO MEI, CHEN LI, TENG ZUO and XIAOBO HE \\ Department of Hepatobiliary and Laparoscopic Surgery, Renmin Hospital of Wuhan University, \\ Wuhan, Hubei 430060, P.R. China
}

Received April 7, 2015; Accepted February 15, 2016

DOI: $10.3892 / \mathrm{mmr} .2016 .5351$

\begin{abstract}
Acute renal injury caused by acute necrotizing pancreatitis (ANP) is a common complication that is associated with a high rate of mortality. Paeoniflorin is the active ingredient of paeonia radix and exhibits a number of pharmacological effects, such as anti-inflammatory, anticancer, analgesic and immunomodulatory effects. The present study detected the potential treatment effects of paeoniflorin on acute renal injury induced by ANP in a rat model. The optimal dose of paeoniflorin for preventing acute renal injury induced by ANP was determined. Then, the possible protective mechanism of paeoniflorin was investigated. The serum levels of tumor necrosis factor (TNF)- $\alpha$, interleukin (IL)- $1 \beta$ and IL-6 were measured with enzyme-linked immunosorbent assay kits. Renal inflammation and apoptosis were measured by immunohistochemistry and terminal deoxynucleotidyl transferase-mediated dUTP nick end labeling assay. The expression of nitric oxide in kidney tissues was also evaluated. The p38 mitogen-activated protein kinases (MAPKs) were measured by western blotting. The results shown that paeoniflorin may ameliorate acute renal injury following ANP in rats by inhibiting inflammatory responses and renal cell apoptosis. These effects may be associated with the p38MAPK and nuclear factor- $\kappa \mathrm{B}$ signal pathway.
\end{abstract}

\section{Introduction}

Acute necrotizing pancreatitis (ANP) is a sudden and serious inflammatory disease of the human digestive system (1). Clinical data has indicated that ANP is a serious inflammatory disease with a systemic inflammatory response and

Correspondence to: Professor Weixing Wang, Department of Hepatobiliary and Laparoscopic Surgery, Renmin Hospital of Wuhan University, 99 Ziyang Road, Wuhan, Hubei 430060, P.R. China E-mail: sate.1lite@163.com

Key words: paeoniflorin, acute necrotizing pancreatitis, acute renal injury, apoptosis, nuclear factor- $\kappa \mathrm{B}, \mathrm{p} 38$ mitogen-activated protein kinases multiple organ dysfunction (2). Although the pathogenesis of ANP is not completely clear, the activation of inflammatory cytokines is key in the etiology (3-5). During ANP, a number of pro-inflammatory cytokines, such as tumor necrosis factor (TNF)- $\alpha$ and interleukin (IL)-6 are released into the blood, which can result in sepsis (6), and mortality (7). Thus, controlling the initial inflammatory response is important for controlling ANP and renal injury induced by ANP. ANP is not only localized to the pancreas but can also activate inflammatory responses throughout the body, it is a systemic disease and can result in systemic inflammatory response syndrome (SIRS) and multiple organ dysfunction (8). ANP-induced renal injury is a frequent and early complication of ANP, and the mortality rate of patients with ANP-induced renal failure is $71.2 \%$ (9). Thus, it is essential to protect renal function in patients with ANP.

Paeoniflorin (PF) is the active ingredient of Radix Paeoniae (10), a traditional herbal medicine and the dried root of Paeonia lactiflora Pallas. PF exhibits numerous pharmacological effects, such as anti-inflammatory, anticancer, analgesic (11) and immunomodulatory effects (12-14). PF can inhibit the systemic inflammatory response and improve the survival of rats with lipopolysaccharide (LPS)-induced sepsis (15). However, the pharmacological effect of PF on ANP and renal injury induced by ANP remains unclear. Evidence demonstrates that the $\mathrm{p} 38$ mitogen-activated protein kinase (MAPK) signaling pathway is closely associated with the nuclear factor (NF)- $\mathrm{BB}$ signaling pathway, which is a critical cell signaling pathway in the inflammatory response. Thus the p38 MAPKs signaling pathway is a focus of research into the inflammatory response. p38MAPKs are members of the MAPKs signaling pathway, which includes p38MAPKs, c-Jun $\mathrm{NH} 2$-terminal kinase (JNK) and extracellular signal-regulated kinase kinase. Its function is associated with the growth and apoptosis of cells (16). The p38 and JNK signaling molecules are key in the inflammatory signaling pathway. p38MAPKs can be triggered by proinflammatory cytokines, such as TNF- $\alpha$ and IL-6 (17,18), and can mediate the inflammatory response induced by LPS (19). The p38MAPK signaling pathway has been demonstrated to be important in the progress of ANP and the organ dysfunction following ANP (20-22).

Thus, the present study used sodium taurocholate to generate an ANP model in rats and investigate the pharmacological 
effect of PF in renal injury induced by ANP, and whether the p38 MAPK pathway is important in this process. The aim of the present study was to obtain the optimal dose of PF for preventing acute renal injury induced by ANP, and to investigate the effects and underlying mechanisms of PF on acute renal injury following ANP.

\section{Materials and methods}

Reagents. $\mathrm{PF}\left(\mathrm{C}_{23} \mathrm{O}_{28} \mathrm{H}_{11} ; \mathrm{FW}, 480.45\right.$; purity $\left.\geq 95 \%\right)$ was purchased from Nanjing Tcm Institute of Chinese Materia Medica (Nanjing, China). Rat TNF- $\alpha$, IL-1 $\beta$ and IL-6 enzyme-linked immunosorbent assay (ELISA) kits were purchased from the Huamei Biology Technology Company (Wuhan, China). Nitric oxide (NO) detection kits were purchased from the Nanjing Jiancheng Bioengineering Institute (Nanjing, China). Rabbit anti-NF-кBp65 (1:200; ab16502), anti-glyceraldehyde 3-phosphate dehydrogenase (GAPDH; 1:2,500; ab8245) and anti-caspase 3 (1:100; ab2302) polyclonal antibodies were purchased from Abcam (Cambridge, UK). Rabbit anti-p38 (1:1,000; 8690) and anti-p-p38 (1:1,000; 4511) polyclonal antibodies were purchased from Cell Signaling Technologies, Inc. (Hercules, CA, USA). The terminal deoxynucleotidyltransferase-mediated dUTP-biotin nick end labeling (TUNEL) assay kits was purchased from Roche Diagnostics (Indianapolis, IN, USA).

Animals. A total of 128 Sprague Dawley (SD) rats (weight, 180-200 g), were purchased from the Center of Experimental Animals of Wuhan University (Wuhan, China). The rats were maintained in specific pathogen-free conditions at room temperature under a 12 h light-dark cycle with ad libitum access to water. The rats underwent fasting prior to operation. The rats were maintained in accordance with the principles of the 1983 Declaration of Helsinki. The present study was approved by the Ethics Committee of Wuhan University (Wuhan, China).

Experimental design. In the first part of the present study, $48 \mathrm{SD}$ rats were randomly divided into six groups (8 rats/group), as follows: i) The sham-operated group; ii) the ANP group; iii) the $\mathrm{ANP}+\mathrm{P} 1$ group (50 $\mathrm{mg} / \mathrm{kg} \mathrm{PF})$; iv) the $\mathrm{ANP}+\mathrm{P} 2$ group (100 mg/kg PF); v) the ANP+P3 group (150 mg/kg PF); and vi) the vehicle group (normal saline at the same volume). In order to induce severe ANP, the rats were fasted overnight and given fresh tap water ad libitum. Anesthesia was administered by intraperitoneal injection with $10 \%$ chloraldurat $(3 \mathrm{ml} / \mathrm{kg}$; Wuhan Goodbio Technology Co., Ltd., Wuhan, China). The pancreatic bile duct was cannulated through the duodenum, and ANP was induced by a standardized retrograde infusion of a freshly prepared $5 \%$ sodium taurocholate solution (1 mg/kg; Sigma-Aldrich, St. Louis, MO, USA) into the biliary-pancreatic duct. Isotonic saline solution $(20 \mathrm{ml} / \mathrm{kg})$ was injected into the back of the rats to compensate for fluid loss. The sham-operated group received isotonic saline solution infusion instead of sodium taurochlorate. For the PF-treated groups, PF was dissolved in vehicle (normal saline) and intravenously injected into the femoral vein 30 min following the generation of the ANP model. The rats were sacrificed $12 \mathrm{~h}$ following the induction of ANP by exsanguination following anesthesia, as the pancreatic damage reached a climax at that time point (23). The effect of PF was evaluated by determining the levels of serum amylase (AMY), serum lipase (LIPA), aspartate-transaminase (AST), alanine-aminotransferase (ALT), and the pathological changes of pancreas shown by hematoxylin \& eosin (H\&E) staining.

Following the initial experiment, the $100 \mathrm{mg} / \mathrm{kg}$ dose of PF was determined to be the optimum dose. Subsequently, 72 SD rats were divided into three groups: i) The $3 \mathrm{~h}$ group; ii) the $6 \mathrm{~h}$ group; and iii) the $12 \mathrm{~h}$ group. These groups were further divided into three subgroups ( 8 rats/subgroup), including the sham-operated group, the ANP group and the ANP+PF group (PF group in the figures). For each part of study the rats were sacrificed by exsanguination under anesthesia. Blood samples were collected from the postcava and plasma was collected following centrifugation at $12,000 \mathrm{x}$ g for $10 \mathrm{~min}$ at $4^{\circ} \mathrm{C}$. The pancreas and kidneys were harvested and immediately frozen in liquid nitrogen, after which they were stored at $-80^{\circ} \mathrm{C}$ for subsequent experiments. Sections of the pancreas and kidneys were fixed in $4 \%$ paraformaldehyde (Wuhan Goodbio Technology Co., Ltd.).

Enzyme assay. The serum levels of AMY, LIPA, AST, ALT, BUN and $\mathrm{Cr}$ were measured using the Automatic Biochemistry Analyzer (Olympus Corporation, Tokyo, Japan), according to a standard technique (24).

Histopathological examination. The paraffin-embedded tissues were cut into 3- $\mu \mathrm{m}$ sections for pathological examination by $H \& E$ staining. The $H \& E$ results were observed under a light microscope (Olympus BX53; Olympus Corporation) by two experienced pathologists who were blinded to the groups. The pancreatic pathological scores were measured according to the degree of edema, inflammation, vacuolization and necrosis as described by Schmidt et al (25). The kidney pathology score was used for evaluating the severity of the renal injury. For each kidney, 100 cortical tubules from at least 10 different views were analyzed. Higher scores represented more severe damage (maximum score per tubule was 10 ), with points given for the following: The presence and extent of tubular epithelial cell flattening (1 point), brush border loss (1 point), cell membrane bleb formation (1 or 2 points), cytoplasmic vacuolization (1 point), cell necrosis (1 or 2 points), interstitial edema (1 point) and tubular lumen obstruction (1 or 2 points) (26).

Enzyme-linked immunosorbent assay (ELISA). The serum levels of TNF- $\alpha$, IL- $1 \beta$ and IL- 6 were measured using ELISA kits, according to the manufacturer's instructions.

Immunohistochemistry assay. The paraffin-embedded kidney tissues were cut into $3-\mu \mathrm{m}$ sections, and the levels of NF- $\kappa \mathrm{B}$ and caspase-3 were determined by immunohistochemical analyses. Briefly, sections were deparaffinized and dehydrated using a graded series of ethanol solutions. The slides were immersed in $10 \mathrm{mM}$ citrate buffer ( $\mathrm{pH}$ 6.0) and boiled for $15 \mathrm{~min}$ in a microwave for antigen retrieval. Then the slides were allowed to cool at room temperature. Hydrogen peroxidase $(0.3 \%)$ was used to halt the endogenous peroxidase activity for $15 \mathrm{~min}$ at room temperature. Non-specific binding was blocked by incubation with goat serum (5\%) for $10 \mathrm{~min}$, after which the sections were 
Table I. Effect of paeoniflorin on enzyme levels.

\begin{tabular}{|c|c|c|c|c|}
\hline Group & AMY (U/1) & LIPA (U/1) & $\operatorname{ALT}(\mathrm{U} / \mathrm{l})$ & AST (U/l) \\
\hline Sham-operated & $1755.7 \pm 214.0$ & $4417.9 \pm 553.1$ & $40.1 \pm 4.8$ & $127.9 \pm 37.2$ \\
\hline ANP & $8287.5 \pm 1394.5^{\mathrm{a}}$ & $14599.5 \pm 1741.5^{\mathrm{a}}$ & $183.5 \pm 54.6^{\mathrm{a}}$ & $618.8 \pm 165.7^{\mathrm{a}}$ \\
\hline \multicolumn{5}{|c|}{ ANP+Paeoniflorin (mg/kg) } \\
\hline 50 & $7244.1 \pm 793.2^{\mathrm{a}, \mathrm{b}}$ & $14190.3 \pm 803.1^{\mathrm{a}}$ & $158.6 \pm 24.8^{a}$ & $480.3 \pm 70.4^{\mathrm{a}}$ \\
\hline 100 & $6333.1 \pm 683.9^{\mathrm{a}-\mathrm{c}}$ & $12675.0 \pm 735.2^{\mathrm{a}-\mathrm{c}}$ & $114.1 \pm 9.4^{\mathrm{a}-\mathrm{c}}$ & $357.6 \pm 51.7^{\mathrm{a}-\mathrm{c}}$ \\
\hline 150 & $5244.3 \pm 445.8^{\mathrm{a}-\mathrm{c}}$ & $11362.8 \pm 905.0^{\mathrm{a}-\mathrm{c}}$ & $275.2 \pm 84.5^{\mathrm{a}-\mathrm{c}}$ & $514.0 \pm 65.6^{\mathrm{a}}$ \\
\hline NS & $1865.3 \pm 205.9$ & $4489.7 \pm 649.3$ & $50 \pm 17.9$ & $142.6 \pm 29.3$ \\
\hline
\end{tabular}

Data are expressed as the mean \pm standard deviation; $n=8$ in each group. ${ }^{\mathrm{a}} \mathrm{P}<0.05$ vs. the sham-operated group; ${ }^{\text {b }}<0.05$ vs. the ANP group; ${ }^{\mathrm{c}} \mathrm{P}<0.05 \mathrm{vs}$. the paeoniflorin $50 \mathrm{mg} / \mathrm{kg}$ group. AMY, amylase; LIPA, lipase; ALT, alanine-aminotransferase; AST, aspartate-transaminase; ANP, acute necrotizing pancreatitis; NS, normal saline.

incubated overnight at $4^{\circ} \mathrm{C}$ with. rabbit anti-NF- $\mathrm{Bp} 65$ and anti-caspase 3 primary antibodies, followed by incubation with horseradish peroxidase (HRP)-conjugated goat anti-rabbit secondary antibody (1:5,000; 10811; Pierce Biotechnology, Inc., Rockford, IL, USA). The staining results were visualized using 3,5-diaminobenzidine (DAB; Wuhan Goodbio Technology Co., Ltd.) and images of the slides were captured under the BX53 microscope. In each immunohistochemistry staining analysis, phosphate-buffered saline was used instead of the primary antibody as a negative control.

TUNEL. The TUNEL assay was performed for evaluating renal cell apoptosis. The renal paraffin-embedded tissues were cut into $3-\mu \mathrm{m}$ sections as reported in the H\&E and immunohistochemistry assay. The sections were deparaffinized, hydrated and incubated with proteinase-K (Wuhan Goodbio Technology Co., Ltd.) for $15 \mathrm{~min}$ at room temperature. The residual steps were conducted according to the protocol provided by the recommendations in situ cell death detection kit, POD (Roche Diagnostics). Hematoxylin was used for staining the nucleus after DAB staining. The results of TUNEL were observed with the Olympus BX53 microscope. The positive results of TUNEL were brown staining in the nucleus.

NO assay. Kidney tissues were thawed and homogenized in phosphate buffer containing $0.5 \%$ hexadeyltrimethylammmonium bromide (Nanjing Jiancheng Bioengineering Institute). NO production was measured using an NO detection kit, according to the manufacturer's instructions.

Western blot analysis. The fresh kidney tissues were homogenized in ice-cold lysis buffer (Beyotime Institute of Biotechnology, Haimen, China) in the presence of a protease inhibitor cocktail (Wuhan Goodbio Technology Co., Ltd.). Proteins were measured using the Bradford Protein Assay with bovine serum albumin (Beyotime Institute of Biotechnology) as a standard. In brief, equal quantities of protein samples were separated on $10 \%$ sodium dodecyl sulfate-polyacrylamide gels and then transferred to a polyvinylidene difluoride membrane (EMD Millipore, Billerica, MA, USA). The membrane was blocked with 5\% skimmed milk in TBST buffer (Tris-buffered saline containing $0.1 \%$
Tween-20) at room temperature for $2 \mathrm{~h}$ and then incubated with a rabbit polyclonal anti-GAPDH antibody (1:2,500, Abcam), rabbit polyclonal antibody anti-P38 (1:1,000, Cell Signaling Technologies, Inc.) and rabbit polyclonal anti-p-P38 antibody (1:1,000, Cell Signaling Technologies, Inc.) at $4^{\circ} \mathrm{C}$ overnight. After extensive rinsing with TBST, the blots were incubated with secondary antibody HRP-conjugated goat anti-rabbit (1:5,000, Pierce Biotechnology, Inc.) at room temperature for $1.5 \mathrm{~h}$, and then detected the expression of GAPDH, P38 and p-P38 by enhanced chemiluminescent reagent (Immobilon Western HRP Substrate; EMD Millipore). The intensities of the bands on the western blots were quantified using Quantity One software, version 4.6.2 (Bio-Rad Laboratories, Inc., Hercules, CA, USA).

Statistical analysis. The data are presented as the mean \pm standard deviation. Data analyses were conducted using SPSS software, version 19.0 (IBM SPSS, Armonk, NY, USA). Data between all groups was compared by one-way analysis of variance. $\mathrm{P}<0.05$ was considered to indicate a statistically significant difference.

\section{Results}

Optimum dose of PF. The present study analyzed the serum AMY, LIPA, ALT and AST levels in ANP rats treated with various doses of PF $(50,100$ and $150 \mathrm{mg} / \mathrm{kg})$ in order to determine the optimum dose of PF. All doses of PF were able to significantly reduce the levels of AMY and LIPA, as compared with the ANP group $(\mathrm{P}<0.05)$. However, the $100 \mathrm{mg} / \mathrm{kg} \mathrm{PF}$ group was the only PF-treated group in which both the levels of AST and ALT were significantly decreased, as compared with the ANP group. Therefore, $100 \mathrm{mg} / \mathrm{kg}$ PF was selected as the optimum dose for treating ANP (Table I).

Histopathological assay. Representative pathological changes in pancreatic tissue are shown in the Fig. 1. Normal histological features of the pancreas were observed in the sham-operated group (Fig. 1A). In the ANP group, pancreatic edema, interstitial leukocyte infiltration, hemorrhage and necrosis were observed (Fig. 1B). In the ANP+100 mg/kg PF group, the severity of pancreatic histological injuries was significantly 
A

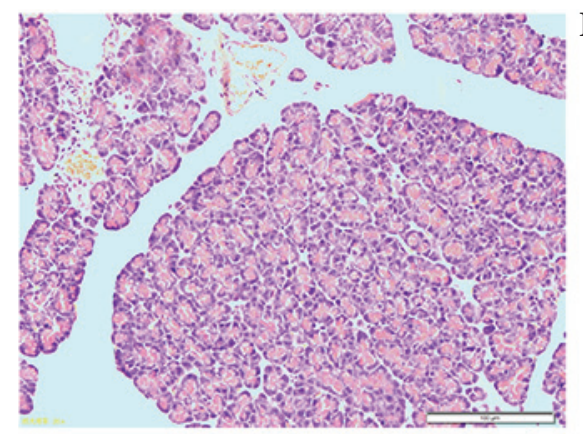

B

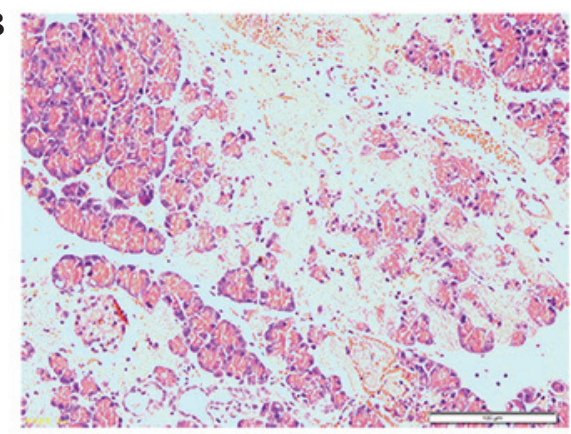

C

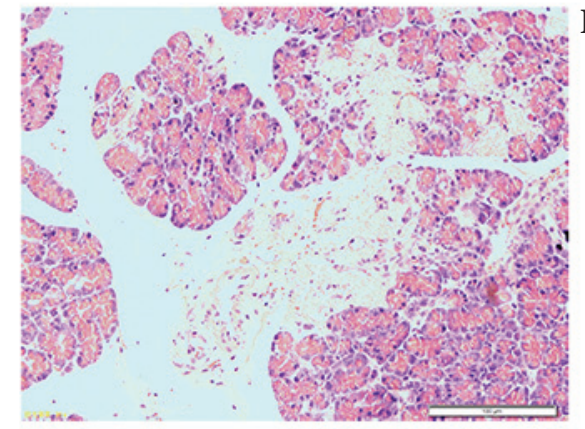

D

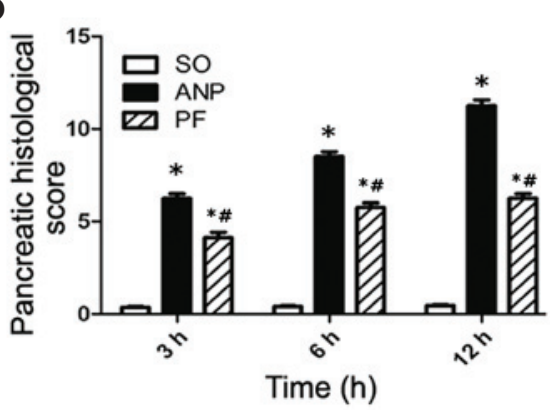

Figure 1. Morphological changes in pancreatic tissue at $12 \mathrm{~h}$ and the pancreatic histological score at different time points. Hematoxylin and eosin staining was used to examine the pathological changes (original magnification, x200). (A) The sham-operated group, (B) the ANP group, (C) the PF group and (D) the pancreatic histological score at corresponding times. ${ }^{*} \mathrm{P}<0.05$ vs. the sham-operated group; ${ }^{*} \mathrm{P}<0.05$ vs. the ANP group. SO, sham-operated; ANP, acute necrotizing pancreatitis; $\mathrm{PF}$, paeoniflorin.

A

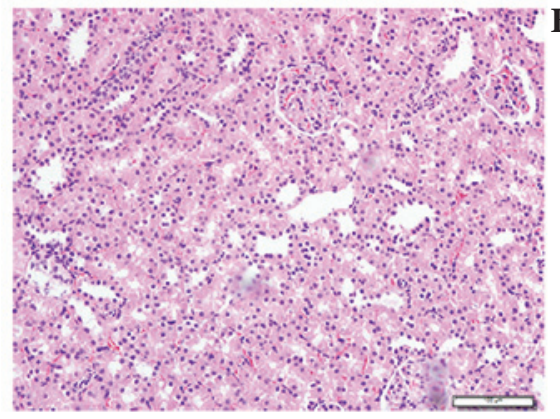

C

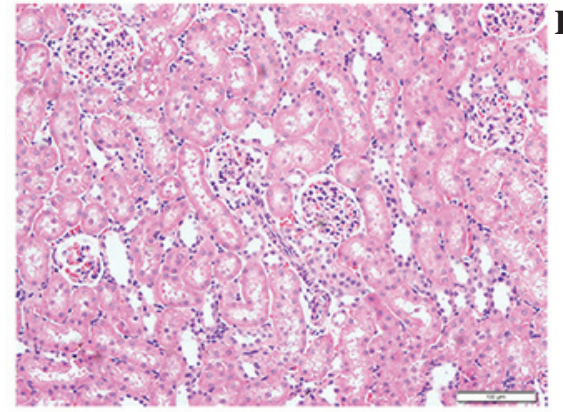

B
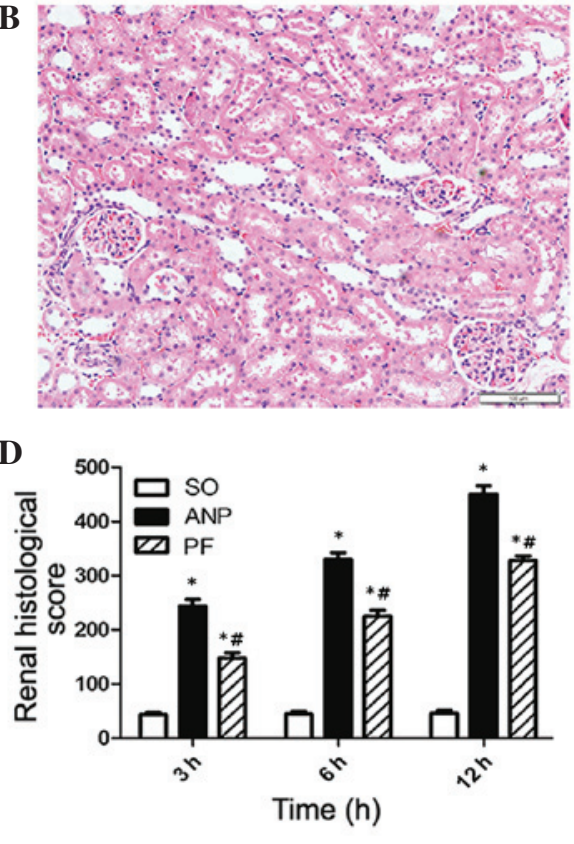

Figure 2. Morphological changes in kidney tissues at $12 \mathrm{~h}$ and the kidney pathological scores at different time points. Hematoxylin and eosin staining was used to examine the pathological changes (original magnification, x200). (A) The sham-operated group, (B) the ANP group, (C) the PF group and (D) the renal histological score at corresponding times. ${ }^{*} \mathrm{P}<0.05$ vs. the sham-operated group; ${ }^{\#} \mathrm{P}<0.05$ vs. the ANP group. SO, sham-operated; ANP, acute necrotizing pancreatitis; $\mathrm{PF}$, paeoniflorin.

reduced compared with the ANP group (Fig. 1C). As shown in Fig. 1D the histopathological score in the pancreas was lower in the PF group compared with that in the ANP group at the corresponding time points $(\mathrm{P}<0.05)$.

To examine the effect of PF on acute renal injury induced by ANP, the pathological changes in the kidney were analyzed
3, 6 and $12 \mathrm{~h}$ after rat ANP models were successfully generated. The renal damage was shown to be the most severe at the $12 \mathrm{~h}$ time point. The loss of brush border, cell necrosis, sloughing of tubular epithelial cell, cast formation and dilation of tubules in the cortex were observed clearly in the ANP group. The ANP+PF group had less severe features of renal 
A

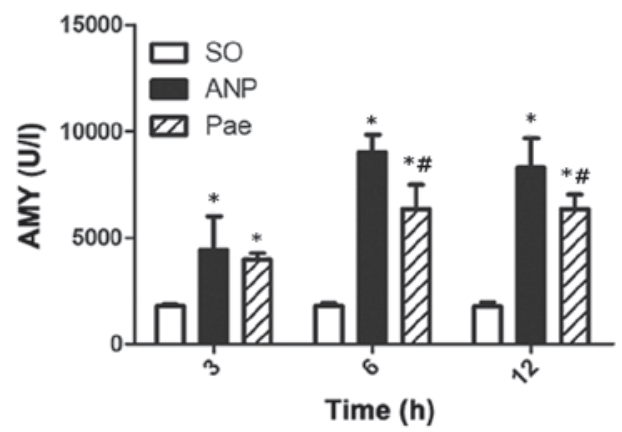

C

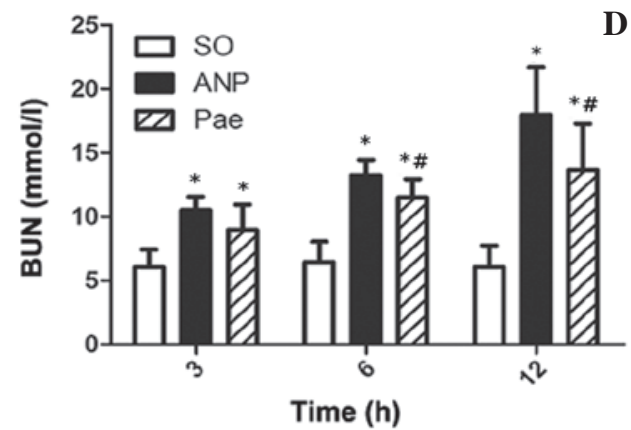

B

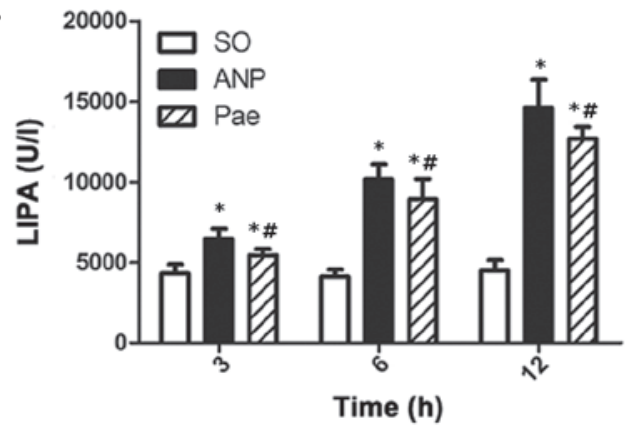

D

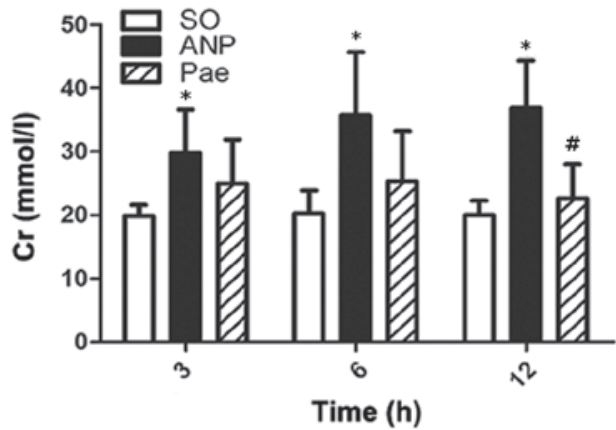

Figure 3. Serum levels of AMY, LIPA, BUN and Cr in all groups. Serum levels of (A) AMY, (B) LIPA, (C) BUN and (D) Cr. Data are expressed as the mean \pm standard deviation; $n=8$ in each group. ${ }^{*} \mathrm{P}<0.05$ vs. the sham-operated group; ${ }^{*} \mathrm{P}<0.05$ vs. the ANP group. SO, sham-operated; ANP, acute necrotizing pancreatitis; PF, paeoniflorin; AMY, amylase; LIPA, lipase; BUN, blood urea nitrogen; Cr, creatine.

injury and the renal histological scores were significantly decreased compared with the ANP group at the corresponding time points as shown in Fig. $2(\mathrm{P}<0.05)$.

Analysis of serum AMY, LIPA, BUN and Cr. Compared with the levels of AMY, LIPA, BUN and $\mathrm{Cr}$ in the shame-operated group, the levels in the ANP group were significantly increased at each time point (Fig. 3). Peak serum AMY level was observed at the $6 \mathrm{~h}$ time point in the ANP group and the peak serum LIPA, BUN and Cr levels were observed at the $12 \mathrm{~h}$ time point. In the $\mathrm{ANP}+\mathrm{PF}$ groups the serum enzyme levels were significantly reduced at the corresponding time points compared with the ANP group $(\mathrm{P}<0.05)$.

ELISA assay. PF reduced the serum levels of TNF- $\alpha$, IL-1 $\beta$ and IL- 6 in the ANP rats. The serum levels of TNF- $\alpha$, IL- $1 \beta$ and IL- 6 were determined using ELISA. It was found that the serum levels of TNF- $\alpha$, IL- $1 \beta$ and IL- 6 were progressively upregulated from 3 to $12 \mathrm{~h}$. The ANP group showed significantly higher levels of TNF- $\alpha$, IL- $1 \beta$ and IL- 6 compared with the sham-operated group. The PF treatment resulted in a marked decrease of serums of TNF- $\alpha$, IL-1 $\beta$ and IL-6, however, the levels of the enzymes in the PF group were significantly higher than the sham-operated group at each time point (Table II).

Immunohistochemistry analysis of $N F-\kappa B$ and caspase-3 levels, and the ratio of apoptotic cells in the renal tissue by TUNEL. In order to detect the degree of inflammation in renal tissues, immunostaining of $\mathrm{NF}-\kappa \mathrm{B}$ was measured in the kidney samples at the $12 \mathrm{~h}$ time point in each group. In the $\mathrm{ANP}+\mathrm{PF}$ group, the expression of $\mathrm{NF}-\kappa \mathrm{B}$ was lower than in the ANP group (Fig. 4A). To identify the effects of PF on apoptotic changes in renal tissues, caspase-3 protein expression was detected with immunohistochemistry. A marked increase in caspase-3 staining was found in the nucleus in the ANP group. In the ANP+PF group the expression of caspase-3 was markedly decreased (Fig. 4B). To further confirm the apoptotic changes, numbers of TUNEL-positive cells were measured. The number of TUNEL-positive cells increased in the ANP group compared with those in sham-operated group. PF attenuated the increase of TUNEL-positive cells number in renal tissue (Fig. 4C). The ratios of positively stained cells were determined and it was shown that the number of cells expression $\mathrm{NF}-\kappa \mathrm{B}$ and caspase -3 were significantly decreased in the ANP+PF group, as compared with the ANP group $(\mathrm{P}<0.05$; Fig. 4D). Furthermore, the numbers of TUNEL-positive cells were significantly decreased in the ANP+PF group, as compared with the ANP group $(\mathrm{P}<0.05$; Fig. 4D).

PF decreases renal NO production. The levels of NO in renal tissues from the ANP group were markedly increased compared with those in the sham-operated group. However, treatment with PF significantly reduced the NO production (Fig. 5).

Role of the p38 MAPK pathway in the effect of PF in renal injury induced by ANP. The p38 MAPK signaling pathway can regulate the expression of $\mathrm{NF}-\kappa \mathrm{B}$ in numerous inflammatory diseases. Therefore, this study detected the effect of PF on the activation of p38 MAPKs in renal tissues using western blot analysis. As shown in the Fig. 6, the ANP group exhibited a higher ratio of p-p38/p38 compared with the sham-operated group. Furthermore, the ANP+PF group exhibited a significant decrease in the ratio of $\mathrm{p}-\mathrm{p} 38 / \mathrm{p} 38$ compared with the ANP group at the $12 \mathrm{~h}$ time point $(\mathrm{P}<0.05)$. 

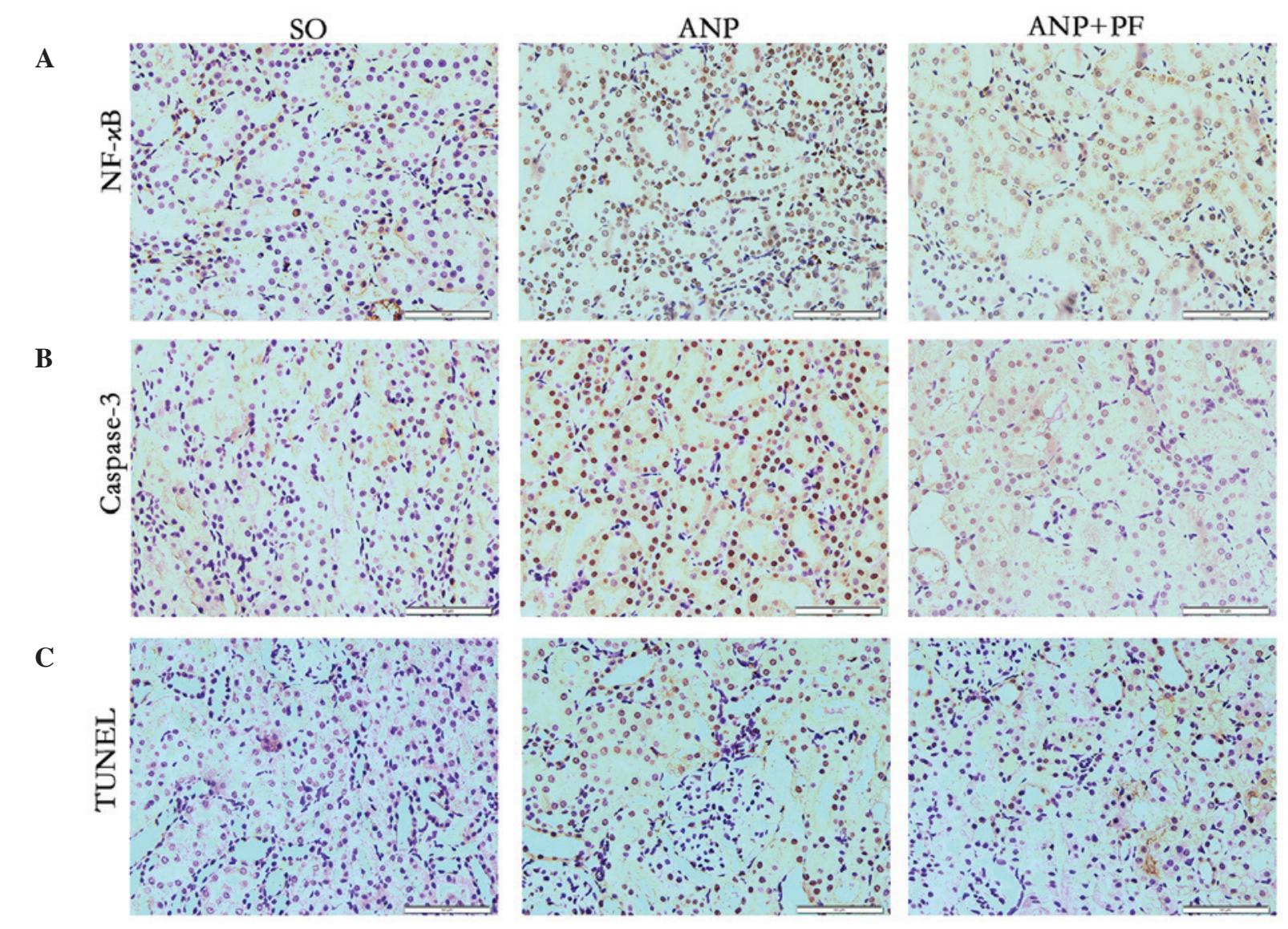

D
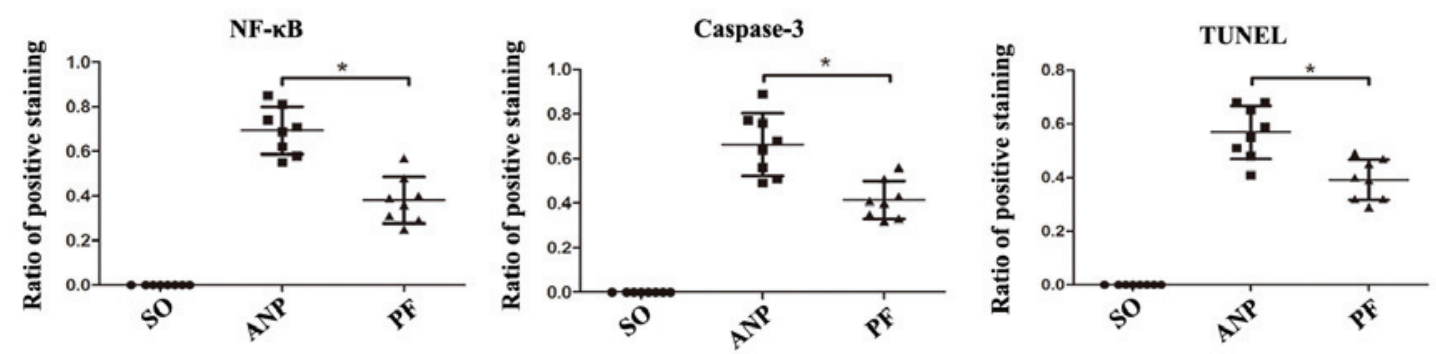

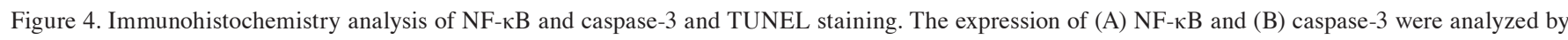
immunohistochemistry and (C) TUNEL staining was performed to determine the number of apoptotic cells in the renal tissues (magnification, $\mathrm{x} 400$ ). (D) The ratio of positively-stained cells was determined. "P<0.05 vs. the ANP group. NF- $\mathrm{BB}$, nuclear factor- $\mathrm{kB}$; TUNEL, terminal deoxynucleotidyl transferase-mediated dUTP nick end labeling; SO, sham-operated; ANP, acute necrotizing pancreatitis; PF, paeoniflorin.

\section{Discussion}

This study is the first to observe the therapeutic effect of PF on ANP and the acute renal injury induced by ANP in rat models. PF is one of the active ingredients of Radix Paeoniae, and it is an important traditional herbal medicine with a number of pharmacological effects, including antihyperlipidemic and anti-inflammatory effects. The results of this study showed that PF can ameliorate ANP and protect the kidneys in ANP. This effect was demonstrated by the serum levels of enzymes and the histological changes in the pancreas and kidneys. Acute renal injury is a common complication of ANP and it is associated with increased risk of mortality (27). The mechanism of the acute renal injury following ANP is complicated. The inflammatory cascades that are initiated by endothelial dysfunction can be augmented by the generation of pro-inflammatory cytokines, such as TNF- $\alpha$, IL- 1 and
IL-6. Using ELISA, the serum levels of the TNF- $\alpha$, IL-1 $\beta$ and IL-6 were shown to be lower in the PF+ANP group compared with the ANP group at each time point. In a previous study by Jiang et al (15), PF was shown to inhibit systemic inflammation and improve survival in the experimental rat models of sepsis.

Another important mechanism underlying the development of acute renal injury following ANP is acute ischemia (28). ANP results in a decreased circulating blood volume, which causes renal ischemia due to decreased blood flow to the kidneys. Ischemia results in apoptosis of renal cells which reduces kidney function. Therefore, in order to investigate the effect of PF on kidney cell apoptosis, a TUNEL assay was conducted and the expression of caspase-3 was analyzed. The ratio of the TUNEL-positive cells was shown to increase in the ANP groups and the majority of TUNEL-positive cells were located at the cortex of the 
Table II. Serum levels of TNF- $\alpha$, IL-1 $\beta$ and IL-6.

\begin{tabular}{|c|c|c|c|}
\hline Group & TNF- $\alpha(\mathrm{pg} / \mathrm{ml})$ & $\mathrm{IL}-1 \beta(\mathrm{pg} / \mathrm{ml})$ & IL-6 (pg/ml) \\
\hline \multicolumn{4}{|c|}{ Sham-operated } \\
\hline $3 \mathrm{~h}$ & $154.78 \pm 11.94$ & $106.21 \pm 6.52$ & $113.36 \pm 9.77$ \\
\hline $6 \mathrm{~h}$ & $155.84 \pm 14.59$ & $103.98 \pm 6.28$ & $116.56 \pm 11.17$ \\
\hline $12 \mathrm{~h}$ & $152.45 \pm 12.83$ & $105.89 \pm 9.02$ & $118.78 \pm 11.43$ \\
\hline \multicolumn{4}{|l|}{ ANP } \\
\hline $3 \mathrm{~h}$ & $251.39 \pm 18.06^{\mathrm{a}}$ & $257.50 \pm 16.31^{\mathrm{a}}$ & $271.44 \pm 17.00^{\mathrm{a}}$ \\
\hline $6 \mathrm{~h}$ & $317.35 \pm 20.76^{\mathrm{a}}$ & $351.41 \pm 14.94^{\mathrm{a}}$ & $355.00 \pm 27.80^{\mathrm{a}}$ \\
\hline $12 \mathrm{~h}$ & $366.90 \pm 13.13^{\mathrm{a}}$ & $430.39 \pm 26.26^{\mathrm{a}}$ & $441.64 \pm 31.19^{\mathrm{a}}$ \\
\hline \multicolumn{4}{|c|}{ ANP+Paeoniflorin } \\
\hline $3 \mathrm{~h}$ & $189.44 \pm 11.84^{\mathrm{a}, \mathrm{b}}$ & $178.54 \pm 13.23^{\mathrm{a}, \mathrm{b}}$ & $173.33 \pm 15.03^{\mathrm{a}, \mathrm{b}}$ \\
\hline $6 \mathrm{~h}$ & $261.88 \pm 16.47^{\mathrm{a}, \mathrm{b}}$ & $275.76 \pm 20.28^{\mathrm{a}, \mathrm{b}}$ & $244.51 \pm 15.37^{\mathrm{a}, \mathrm{b}}$ \\
\hline $12 \mathrm{~h}$ & $286.23 \pm 11.23^{\mathrm{a}, \mathrm{b}}$ & $315.60 \pm 11.04^{\mathrm{a}, \mathrm{b}}$ & $288.29 \pm 12.71^{\mathrm{a}, \mathrm{b}}$ \\
\hline
\end{tabular}

Serum levels of TNF- $\alpha$, IL-1 $\beta$ and IL- 6 measured by enzyme-linked immunosorbent assay kits. Data are expressed as the mean \pm standard deviation; $\mathrm{n}=8$ in each group. ${ }^{\mathrm{P}} \mathrm{P}<0.05$ vs. the sham-operated group; ${ }^{\mathrm{b}} \mathrm{P}<0.05$ vs. the ANP group. ANP, acute necrotizing pancreatitis; $\mathrm{TNF}-\alpha$, tumor necrosis factor- $\alpha$; IL, interleukin.

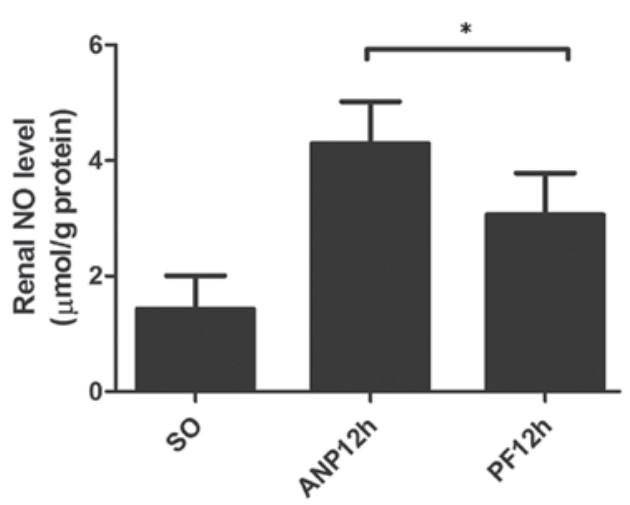

Figure 5. PF decreases renal NO production in acute renal injury induced by ANP. Kidneys were collected $12 \mathrm{~h}$ after the ANP rat models were induced Data are expressed as the mean \pm standard deviation. ${ }^{*} \mathrm{P}<0.05$ vs. the ANP group. SO, sham-operated; ANP, acute necrotizing pancreatitis; PF, paeoniflorin.

kidney. The mechanisms underlying the apoptosis of renal tissues are associated with cellular cytotoxicity and DNA damage. In addition, $\mathrm{NO}$ was shown to have an important role in the initiation of apoptosis in experimental renal IR (29). A previous study demonstrated that NO production resulted in cytotoxicity and DNA damage (29). In the present study, PF was shown to inhibit NO-mediated apoptosis in acute renal injury induced by ANP. The results showed that PF was able to ameliorate NO production and inhibit tubular cell apoptosis. PF is known to promote the dilatation of blood vessels, which may increase blood perfusion to the renal cortex and inhibit cell apoptosis. Therefore, these results suggested that PF may attenuate renal damage by reducing NO-induced apoptosis of renal cells.

Caspase-3, which is a member of the caspase family that includes caspase-1 to caspase-12, has a key function in apoptosis (30). In a previous study, the role of caspase- 3 in apoptosis was closely associated with the Bax/Bcl-2 signaling
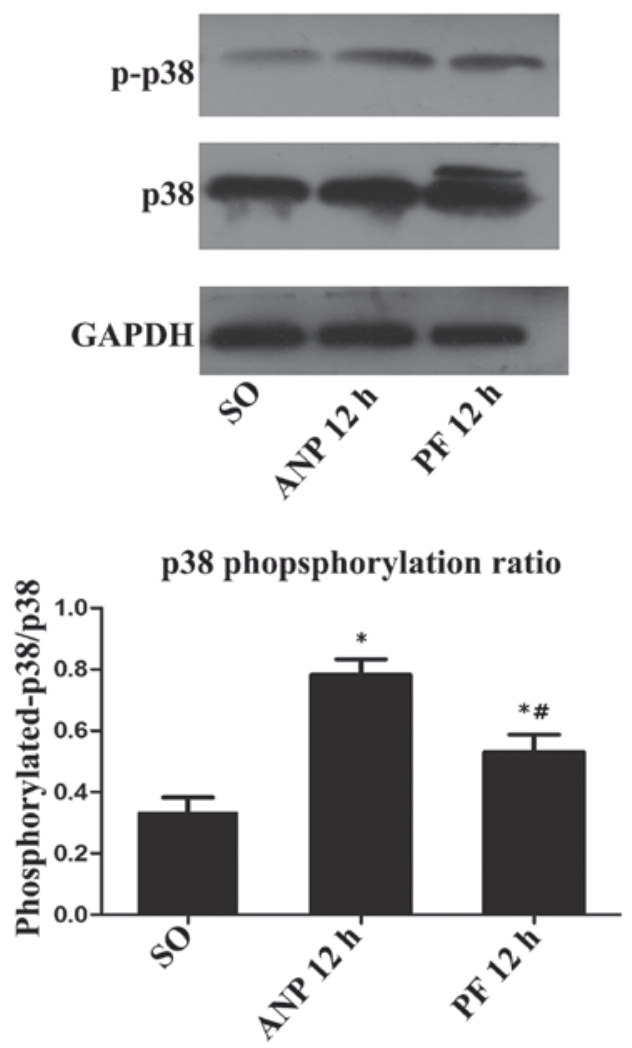

Figure 6. Levels of p-p38 in the kidney tissues at the $12 \mathrm{~h}$ time point. Western blot analysis was used to determine the protein levels. ${ }^{*} \mathrm{P}<0.05$ vs. the sham-operated group; ${ }^{\#} \mathrm{P}<0.05$ vs. the ANP group. SO, sham-operated; ANP, acute necrotizing pancreatitis; PF, paeoniflorin; p-, phosphorylated; GAPDH, glyceraldehyde 3-phosphate dehydrogenase.

pathway. Activation of the initiator caspase- 8 is triggered by the extrinsic death signaling pathway (31). The other initiator caspase, caspase-9, is predominantly activated by the release of pro-apoptotic proteins in the intrinsic pathway (32). The 
initiator caspases culminate and trigger downstream caspase-3, which is the core executioner caspase during the extrinsic and intrinsic apoptosis pathways. In the present study, PF treatment significantly suppressed the expression of caspase- 3 in renal tissues in the ANP rat model. These results suggested that PF may inhibit apoptosis.

The alterations in renal apoptosis and inflammation in the ANP rat model were closely associated, since inflammation has been shown to lead to apoptosis. Inflammatory cytokines, such as IL-1, TNF- $\alpha$ and IL-6, promote cell death by inducing the expression of connective molecules on the surface of the blood vessel endothelium, and these molecules can promote the inflammatory cells to form multinucleated cells that have been associated with apoptosis (33). NF- $\kappa \mathrm{B}$ is essential in the inflammatory response to acute pancreatitis as well as in apoptosis $(34,35)$. The most common forms of $\mathrm{NF}-\kappa \mathrm{B}$ are heterodimers composed of p50 and p65 or p52 and p65 (36). In the cytoplasm, $\mathrm{NF}-\kappa \mathrm{B}$ exists as an inactive form associated with its regulatory protein, $\mathrm{I} \kappa \mathrm{B}$. During inflammation, inflammatory cytokines such as IL-1, TNF- $\alpha$ and IL- 6 activate NF- $\kappa$ B by phosphorylating $\mathrm{I} \kappa \mathrm{B}$; phosphorylated $\mathrm{I} \kappa \mathrm{B}$ releases $\mathrm{NF}-\kappa \mathrm{B}$ dimers from the cytoplasmic NF- $\mathrm{B}-\mathrm{I} \kappa \mathrm{B}$ complex, such that they are able to translocate into the nucleus (37). The p38MAPK signaling pathway, a classic MAPK signal transduction pathway, has been shown to be important in cell proliferation, differentiation, cytokine synthesis and T-cell activation (38). When stimulated by specific inflammatory cytokines, pathogens or cell stress, p38MAPK is activated, phosphorylated and transferred into the nucleus. The phosphorylated p38MAPKs can activate $\mathrm{I} \kappa \mathrm{B}$ and induce the $\mathrm{NF}-\kappa \mathrm{B}$ signal transduction pathway. In the present study, immunohistochemistry results demonstrated an increase in the level of NF- $\mathrm{BB}$ in the ANP group, as compared with the sham-operated group, and a significant decrease in the level of NF- $\kappa \mathrm{B}$ in the $\mathrm{PF}+\mathrm{ANP}$ group, as compared with the ANP group. Western blotting demonstrated that PF treatment decreased the level of phosphorylated p38MAPKs. Thus, the anti-inflammatory action of PF may be associated with the p38MAPKs/NF- $\kappa$ B signaling pathway. A limitation of this study is that no experiment was conducted using a p38MAPKs signal pathway inhibitor. It remains to be determined whether the p38MAPK/NF- $\kappa \mathrm{B}$ signaling pathway is the only signal transduction pathway mediating the effects of PF. Although further investigation is required to determine the precise mechanism underlying the effects of $\mathrm{PF}$, the present results demonstrate that PF does exhibit a protective effect against ANP-induced renal injury.

In conclusion, PF prevented ANP-induced acute renal injury by inhibiting inflammation and apoptosis. Thus, PF may be a potential therapeutic agent for the treatment or prevention of ANP and acute renal injury induced by ANP.

\section{Acknowledgements}

The present study was supported by the National Natural Science Foundation of China (grant no. 81370562) and the Projects of Medical and Health Technology Development Program in Shandong province (grant no. 2013GGB14096). The authors would like to thank Dr. Yongfei Tang of Department of Pathology, (Renmin Hospital, Wuhan University).

\section{References}

1. Fritz S, Hartwig W, Lehmann R, Will-Schweiger K, Kommerell M, Hackert T, Schneider L, Büchler MW and Werner J: Prophylactic antibiotic treatment is superior to therapy on-demand in experimental necrotising pancreatitis. Cri Care 12: R141, 2008.

2. Bhatia M, Brady M, Shokuhi S, Christmas S, Neoptolemos JP and Slavin J: Inflammatory mediators in acute pancreatitis. J Pathol 190: 117-125, 2000.

3. Büchler MW, Gloor B, Müller CA, Friess H, Seiler CA and Uhl W: Acute necrotizing pancreatitis: Treatment strategy according to the status of infection. Ann Surg 232: 619-626, 2000.

4. Norman JG, Fink G, Franz M, Guffey J, Carter G, Davison B, Sexton C and Glaccum M: Active interleukin-1 receptor required for maximal progression of acute pancreatitis. Ann Surg 223: 163-169, 1996.

5. Felderbauer P, Müller C, Bulut K, Belyaev O, Schmitz F, Uhl W and Schmidt WE: Pathophysiology and treatment of acute pancreatitis: New therapeutic targets-a ray of hope? Basic Clin Pharmacol Toxicol 97: 342-350, 2005.

6. Cohen J: The immunopathogenesis of sepsis. Nature 420: 885-891, 2002.

7. Hong W, Dong L, Huang Q, Wu W, Wu J and Wang Y: Prediction of severe acute pancreatitis using classification and regression tree analysis. Dig Dis Sci 56: 3664-3671, 2011.

8. Zhang XP, Zhang L, Chen LJ, Cheng QH, Wang JM, Cai W, Shen HP and Cai J: Influence of dexamethasone on inflammatory mediators and NF-kappaB expression in multiple organs of rats with severe acute pancreatitis. World J Gastroenterol 13: 548-556, 2007.

9. Herrera Gutiérrez ME, Seller Pérez G, de La Rubia De Gracia C, Chaparro Sánchez MJ and Nacle López B: Acute renal failure profile and prognostic value in severe acute pancreatitis. Med Clin (Barc) 115: 721-725, 2000 (In Spanish).

10. Liu DZ, Xie KQ, Ji XQ, Ye Y, Jiang CL and Zhu XZ: Neuroprotective effect of paeoniflorin on cerebral ischemic rat by activating adenosine A1 receptor in a manner different from its classical agonists. Br J Pharmacol 146: 604-611, 2005.

11. Sugishita E, Amagaya S and Ogihara Y: Studies on the combination of Glycyrrhizae Radix in Shakuyakukanzo-To. J Pharmacobiodyn 7: 427-435, 1984.

12. Hu ZY, Xu L, Yan R, Huang Y, Liu G, Zhou WX and Zhang YX: Advance in studies on effect of paeoniflorin on nervous system. Zhongguo Zhong Yao Za Zhi 38: 297-301, 2013 (In Chinese).

13. Zhang W and Dai SM: Mechanisms involved in the therapeutic effects of Paeonia lactiflora Pallas in rheumatoid arthritis. Int Immunopharmacol 14: 27-31, 2012.

14. Yamahara J, Yamada T, Kimura H, Sawada T and Fujimura H: Biologically active principles of crude drugs. II. Anti-allergic principles in 'Shoseiryu-To' anti-inflammatory properties of paeoniflorin and its derivatives. J Pharmacobiodyn 5: 921-929, 1982.

15. Jiang WL, Chen XG, Zhu HB, Gao YB, Tian JW and Fu FH: Paeoniflorin inhibits systemic inflammation and improves survival in experimental sepsis. Basic Clin Pharmacol Toxicol 105: 64-71, 2009.

16. Huh JE, Kang KS, Chae C, Kim HM, Ahn KS and Kim SH: Roles of p38 and JNK mitogen-activated protein kinase pathways during cantharidin-induced apoptosis in U937 cells. Biochem Pharmacol 67: 1811-1818, 2004.

17. Lv KY, Yu XY, Bai YS, Zhu SH, Tang HT, Ben DF, Xiao SC, Wang GY, Ma B and Xia ZF: Role of inhibition of p38 mitogen-activated protein kinase in liver dysfunction after hemorrhagic shock and resuscitation. J Surg Res 178: 827-832, 2012.

18. Widmann C, Gibson S, Jarpe MB and Johnson GL: Mitogen-activated protein kinase: Conservation of a three-kinase module from yeast to human. Physiol Rev 79: 143-180, 1999.

19. Schnyder-Candrian S, Quesniaux VF, Di Padova F, Maillet I, Noulin N, Couillin I, Moser R, Erard F, Vargaftig BB, Ryffel B and Schnyder B: Dual effects of p38 MAPK on TNF-dependent bronchoconstriction and TNF-independent neutrophil recruitment in lipopolysaccharide-induced acute respiratory distress syndrome. J Immunol 175: 262-269, 2005.

20. Wang XY, Tang QQ, Zhang JL, Fang MY and Li YX: Effect of SB203580 on pathologic change of pancreatic tissue and expression of TNF- $\alpha$ and IL-1 $\beta$ in rats with severe acute pancreatitis. Eur Rev Med Pharmacol Sci 18: 338-343, 2014.

21. Lv W, Lv C, Yu S, Yang Y, Kong H, Xie J, Sun H, Andersson R, $\mathrm{Xu}$ D, Chen B and Zhou M: Lipoxin A4 attenuation of endothelial inflammation response mimicking pancreatitis-induced lung injury. Exp Biol Med (Maywood) 238: 1388-1395, 2013. 
22. Pereda J, Sabater L, Cassinello N, Gómez-Cambronero L, Closa D, Folch-Puy E, Aparisi L, Calvete J, Cerdá M, Lledó S, et al: Effect of simultaneous inhibition of TNF-alpha production and xanthine oxidase in experimental acute pancreatitis: The role of mitogen activated protein kinases. Ann Surg 240: 108-116, 2004

23. Paszkowski AS, Rau B, Mayer JM, Möller P and Beger HG: Therapeutic application of caspase 1 /interleukin-1beta-converting enzyme inhibitor decreases the death rate in severe acute experimental pancreatitis. Ann Surg 235: 68-76, 2002.

24. Saitoh M, Hasegawa R and Inoue T: Change of calibration method for enzyme assay in clinical biochemistry using automatic analyzer - comparison of calibration methods using $\mathrm{K}$ factor and human standard serum. Eisei Shikenjo Hokoku: 99-101, 1996 (In Japanese).

25. Schmidt J, Rattner DW, Lewandrowski K, Compton CC, Mandavilli U, Knoefel WT and Warshaw AL: A better model of acute pancreatitis for evaluating therapy. Ann Surg 215: 44-56, 1992.

26. Paller MS, Hoidal JR and Ferris TF: Oxygen free radicals in ischemic acute renal failure in the rat. J Clin Invest 74: 1156-1164, 1984.

27. Zhao K, Chen C, Shi Q, Deng W, Zuo T, He X, Liu T, Zhao L and Wang W: Inhibition of glycogen synthase kinase-3 $\beta$ attenuates acute kidney injury in sodium taurocholateinduced severe acute pancreatitis in rats. Mol Med Rep 10: 3185-3192, 2014.

28. Jin X, Zhang Y, Li X, Zhang J and Xu D: C-type natriuretic peptide ameliorates ischemia/reperfusion-induced acute kidney injury by inhibiting apoptosis and oxidative stress in rats. Life Sci 117: 40-45, 2014.

29. Viñas JL, Sola A, Genescà M, Alfaro V, Pí F and Hotter G: $\mathrm{NO}$ and NOS isoforms in the development of apoptosis in renal ischemia/reperfusion. Free Radic Biol Med 40: 992-1003, 2006.
30. Falschlehner $\mathrm{C}$ and Boutros $\mathrm{M}$ : Innate immunity: Regulation of caspases by IAP-dependent ubiquitylation. EMBO J 31: 2750-2752, 2012.

31. Kischkel FC, Hellbardt S, Behrmann I, Germer M, Pawlita M, Krammer PH and Peter ME: Cytotoxicity-dependent APO-1 (Fas/CD95)-associated proteins form a death-inducing signaling complex (DISC) with the receptor. EMBO J 14: 5579-5588, 1995 .

32. Hill MM, Adrain C, Duriez PJ, Creagh EM and Martin SJ Analysis of the composition, assembly kinetics and activity of native Apaf-1 apoptosomes. EMBO J 23: 2134-2145, 2004.

33. Hashemi M: The study of pentoxifylline drug effects on renal apoptosis and BCL-2 gene expression changes following ischemic reperfusion injury in rat. Iran J Pharm Res 13: 181-189, 2014.

34. Chen X, Ji B, Han B, Ernst SA, Simeone D and Logsdon CD: NF-kappaB activation in pancreas induces pancreatic and systemic inflammatory response. Gastroenterology 122: 448-457, 2002.

35. Peng Y, Gallagher SF, Haines K, Baksh K and Murr MM: Nuclear factor-kappaB mediates Kupffer cell apoptosis through transcriptional activation of Fas/FasL. J Surg Res 130: 58-65, 2006.

36. Tak PP and Firestein GS: NF-kappaB: A key role in inflammatory diseases. J Clin Invest 107: 7-11, 2001.

37. Thompson JE, Phillips RJ, Erdjument-Bromage H, Tempst P and Ghosh S: I kappa B-beta regulates the persistent response in a biphasic activation of NF-kappa B. Cell 80: 573-582, 1995.

38. Fecher LA, Amaravadi RK and Flaherty KT: The MAPK pathway in melanoma. Curr Opin Oncol 20: 183-189, 2008. 